\title{
BMJ Open Direct non-medical and indirect costs of diabetes and its associated complications in Vietnam: an estimation using national health insurance claims from a cross-sectional survey
}

To cite: Kieu TTM, Trinh HN, Pham HTK, et al. Direct nonmedical and indirect costs of diabetes and its associated complications in Vietnam: an estimation using national health insurance claims from a crosssectional survey. BMJ Open 2020;10:e032303. doi:10.1136/ bmjopen-2019-032303

- Prepublication history and additional material for this paper are available online. To view these files, please visit the journal online (http://dx.doi org/10.1136/bmjopen-2019032303).

Received 18 June 2019 Revised 10 December 2019 Accepted 28 January 2020

Check for updates

(c) Author(s) (or their employer(s)) 2020. Re-use permitted under CC BY-NC. No commercial re-use. See rights and permissions. Published by BMJ.

${ }^{1}$ Department of Pharmaceutical Management and

Pharmacoeconomics, Hanoi University of Pharmacy, Hanoi, Viet Nam

${ }^{2}$ Department for Health Economics, Hanoi Medical University, Hanoi, Viet Nam ${ }^{3}$ Real-World Insights, IQVIA AsiaPacific, Singapore, Singapore

Correspondence to Dr Junice Yi Siu Ng; junice.ng@iqvia.com

\section{ABSTRACT}

Objective The prevalence of diabetes in Vietnam has increased from $2.5 \%$ in 2007 to $5.5 \%$ in 2017 , but the burden of direct non-medical and indirect costs is unknown. The objective of this study was to estimate the direct nonmedical costs and indirect costs due to type 2 diabetes mellitus (T2DM) and its associated complications among Vietnam Health Insurance System (VHIS) enrollees in Vietnam. Design The first phase was a cross-sectional survey of patients with T2DM. In the second phase, data from the previous phase were used to predict direct nonmedical costs and presenteeism costs of VHIS enrollees diagnosed with T2DM based on demographic and clinical characteristics in 2017. The human-capital approach was used for the calculation of indirect costs.

Setting and participants This study recruited 315 patients from a national hospital, a provincial hospital and a district hospital aged 18 or above, diagnosed with T2DM, enrolled in VHIS, and having at least one visit to hospitals between 1 June and 30 July 2018. The VHIS dataset contained 1,395,204 patients with T2DM.

Outcome measures The direct non-medical costs and presenteeism were collected from the survey. Absenteeism costs were estimated from the VHIS database. Costs of premature mortality were calculated based on the estimates from secondary sources.

Results The total direct non-medical and indirect costs were US\$239 million in 2017. Direct non-medical costs were US\$78 million, whereas indirect costs were US\$161 million. Costs of absenteeism, presenteeism and premature mortality corresponded to $17 \%, 73 \%$ and $10 \%$ of the indirect costs. Patients incurred annual mean direct non-medical costs of US\$56. Annual mean absenteeism and presenteeism costs for patients in working age were US\$61 and US\$267, respectively.

Conclusions The impact of T2DM on direct non-medica and indirect costs on diabetes is substantial. Direct nonmedical and absenteeism costs were higher in patients with complications.

\section{INTRODUCTION}

According to the International Diabetes Federation (IDF), the prevalence of diabetes in
Strengths and limitations of this study

The survey population included patients from different levels of facilities, capturing patients with varying severity of complications.

- Simulation of the survey data to population-level was conducted using the national health insurance database, which increases the generalisability of the findings.

- Cost of disability was not included in the study.

- Costs of absenteeism and presenteeism were estimated for the working-age population.

Vietnam has doubled from $2.5 \%$ in 2007 to $5.5 \%$ in $2017 .^{1}$ This poses a notable economic burden on both the government and patients. The healthcare expenditure per person with diabetes has increased from US\$38 (4.2\% of the gross domestic product (GDP)) per capita in 2007 to US $\$ 217$ (9.3\% of GDP) per capita in 2017. ${ }^{1}$ Diabetes and its associated complications impact not only direct medical costs but also direct non-medical costs and productivity. Studies on cost-of-illness of diabetes have reported that direct non-medical costs ranged from $1 \%$ of the total costs in $\mathrm{Mali}^{2}$ to $40 \%$ in Thailand, ${ }^{3}$ and indirect costs accounted for a substantial proportion of the total costs ranging from $12 \%$ in Chennai, India ${ }^{4}$ to $68 \%$ in the African region. ${ }^{5}$

In Vietnam, the national economic burden of diabetes has not been investigated, but two studies reported both direct and indirect costs incurred by patients with T2DM recruited from hospitals in urban areas. ${ }^{67}$ The first study conducted by Nguyen recruited 400 participants from a tertiary hospital and two provincial hospitals into a landmark study between 2006 and 2007 in Hue, a city in central Vietnam. ${ }^{6}$ Participants were 
categorised by annual household income into quintiles. This study found that among the highest income group with an annual household income between US $\$ 972$ and US $\$ 4,484$, direct medical costs accounted for $47 \%$ of the total costs, whereas the lowest income group with an annual household income between US\$63 and US\$312 reported a higher proportion of direct medical costs at $67 \%$. The proportion of direct non-medical costs ranged from $24 \%$ in the lowest income group to $55 \%$ in the middle-income group. The proportion of indirect costs for the lowest income group (12\%) was twice that of the highest income group (6\%). However, no discernible trend was observed for the total costs of diabetes across the income groups. It was also found that the average cost per patient was higher for those with complications (US\$336) than those without (US\$280), although the definition of complication was not specified. In terms of healthcare financing, almost half (48\%) of the participants received financial support from relatives, and $27 \%$ of the participants coped by either selling assets or borrowing money. It should be noted that this study was conducted before the enrolment into national health insurance, also known as Vietnam Health Insurance Scheme (VHIS), was made mandatory in 2015 , and only about one-fifth $(21 \%)$ the participants had health insurance at the point of survey.

Le et al. conducted another cross-sectional study in 2016 among 392 patients with diabetes in a tertiary care facility in Ho Chi Minh City (HCMC). ${ }^{7}$ The authors also reported a higher annual mean cost of diabetes for those with complications (US\$300) than those without complications (US\$140). The direct non-medical costs which constituted only transportation reported by Le et al. were $14 \%$ of the total costs, whereas the study by Nguyen reported that $41 \%$ of total costs were attributed to direct non-medical costs, namely diabetes-related nutritional supplements and transportation. There were also mixed findings on indirect costs from the two studies. The proportion of indirect costs were significantly higher in the study conducted in HCMC (34\%) than Hue (8\%). Additionally, in the study by Nguyen, ${ }^{6}$ it was unclear what constituted indirect costs. Le et al. estimated productivity loss in patients with diabetes based on another study conducted in the USA, whereas presenteeism and unemployment were derived from the primary data. Moreover, the studies were conducted mainly in tertiary and provincial hospitals, which could be more representative of patients with severe complications. The objective of our study was to estimate the burden of direct nonmedical costs and indirect costs among patients with type 2 diabetes mellitus (T2DM) in Vietnam. This is achieved by projecting the results from a cross-sectional survey and extending the results to each VHIS enrollee.

\section{METHODS}

This study adopted a societal perspective. However, the estimation of direct medical costs was conducted in a separate article, due to its length and methodology.

\section{Data sources}

Data sources, which were used to examine the direct non-medical and indirect costs associated with T2DM, included a cross-sectional survey of 315 patients, data from the administrative database of the VHIS, secondary literature, and labour and wage statistics from The National Statistics Office of Vietnam (online supplementary table 1).

\section{Cross-sectional survey}

The cross-sectional survey study has been reported according to the Strengthening and Reporting of Observational Studies in Epidemiology (STROBE) statement guidelines (online supplementary table 2). Between 1 June and 30 July 2018, a total of 315 patients with T2DM were recruited from three health facilities, which were selected to represent national, provincial and district levels of healthcare in Vietnam. Patients were included if they were aged 18 or above, diagnosed with T2DM as noted in their medical records and enrolled in the VHIS. We excluded two illiterate patients who were unable to understand the informed consent form. The nurses referred eligible outpatients or newly admitted inpatients to the research assistants for study participation. Eligible participants were explained the study objectives and written informed consent was obtained. Information on sociodemographics and medical conditions, including the presence of diabetes-related complications, was obtained from the patients' medical records, whereas data on nonmedical costs, presenteeism and disability were collected from respondents through interviews using a structured questionnaire. Due to the proximity of the country and the similar sampling methodology, we calculated the sample size based on the prevalence of diabetes complications in Malaysia, which was $75 \% .^{8}$ To estimate the prevalence of diabetes-related complications with a precision of 0.05 , a $95 \%$ CI, a sample size of 315 was considered to be sufficient for this study.

\section{VHIS database}

The VHIS covers $84 \%$ of the Vietnamese population in $2017 .^{9}$ Its database, which was initiated in 2017, includes information on patient's demographic characteristics, diagnosis, prescription and healthcare utilisation, such as length of stay. For this study, patient-level data were extracted from the database, providing information about the prevalence and costs of diabetes and its complications. Those aged 30 or above with at least one ICD-10 code E11 or had been prescribed with oral hypoglycemic drugs on three separate visits within 2017 were identified as being diagnosed with T2DM. To identify patients with diabetes-related complications, the Diabetes Severity Complications Index (DSCI) score was used and was determined based on the medical conditions recorded within 2017 in the VHIS database. ${ }^{10}$ Patients with a DSCI score of 0 were regarded as not having diabetes-related complications, whereas a DSCI score between 1 and 13 was deemed as having complications. 


\section{Direct non-medical costs}

Questions regarding direct non-medical costs in the survey included non-prescribed supplements or traditional medicine, transport, meals for both patient and caregiver, as well as interests incurred from the loans taken to pay off the medical fees. ${ }^{11}$ In Vietnam, $69 \%$ of the nonagricultural population works in the informal sector. ${ }^{12}$ When faced with unaffordable healthcare or reduced ability to work due to medical conditions, patients would resort to taking interest-bearing loans to pay off medical bills. A generalised linear regression model was built to predict the direct non-medical cost adjusting for age, gender, province of residence and presence of comorbidities, namely hypertension and dyslipidaemia. The parameters estimated from this model were then applied to the VHIS dataset to obtain the estimated direct non-medical cost for each VHIS enrollee with T2DM.

\section{Indirect costs}

A human-capital approach was used for the calculation of indirect cost, which included the costs of absenteeism, presenteeism and premature mortality. Absenteeism and presenteeism were estimated only for the working-age population, that is, between age 30 and 60 for men and between age 30 and 55 for women.

Absenteeism was defined as the total length of stay, and the number of outpatient visits multiplied by 0.5 days. Length of stay and the number of outpatient visits were obtained from the VHIS database.

Presenteeism, or impact of health problems while on the job, was assessed by using the short form of Work Limitations Questionnaire (WLQ) ${ }^{13}$ administered to the survey participants. WLQ was translated and validated in Vietnamese based on the Linguistic Validation Guidance of a Clinical Outcome Assessment outlined by Mapi Research Trust. Briefly, the linguistic validation comprised four steps: (i) forward translation, (ii) backward translation, (iii) cognitive interviews and (iv) proofreading. The resulting WLQ scores from the survey dataset were then used to predict the WLQ scores for the population in the VHIS. First, the survey dataset and the VHIS dataset were combined to find similar people in two datasets. The two datasets are first given labels (ie, survey and database). Then, a logistic regression model was built to predict each individual's probability of occurring in the combined dataset using the following covariates: age, gender, presence of hypertension, dyslipidaemia and diabetes-related complications, length of stay and number of outpatient visits. Next, the dataset was then divided into tertiles based on the predicted probability. Within each tertile, another logistic model was built to predict the WLQ scores of each individual, adjusted using the same covariates in the first model. Finally, presenteeism costs were calculated by extrapolating estimates of productivity loss in the past 2 weeks (the WLQ Loss Score) to 1 year in days (assuming 240 workdays per year).

The lost days of work due to absenteeism and presenteeism were multiplied with the mean daily wage based on the data in 2017 from the Office of General Statistics Viet Nam.

Premature mortality was based on the estimates for 2017 from the Institute for Health Metrics and Evaluation (IHME) and $\operatorname{IDF}^{114}$ and derived using the following formula.

No. of deaths due to T2DM=No. of deaths reported in IDF $\times \frac{\text { No. of T2DM related deaths reported in IHME }}{\text { No }}$

Costs due to mortality were calculated based on the value of future lifetime earnings. A discount rate of $3 \%$ was used.

\section{Sensitivity analyses}

In this study, one-way sensitivity analyses were performed on costs, income and discount rates. The baseline values, ranges and the sources of parameters are listed in table 1.

Probabilistic sensitivity analyses were also conducted by running 10,000 simulations with random selections of all model variable values within their specified ranges. The mean (standard deviation (SD)), minimum and maximum values were reported.

Table 1 Key variables and ranges considered in sensitivity analyses

\begin{tabular}{|c|c|c|c|c|}
\hline Items & $\begin{array}{l}\text { Baseline } \\
\text { value }\end{array}$ & Lower & Upper & Source \\
\hline Direct non-medical costs (US\$) & 55.9 & 34.5 & 73.9 & Simulated data using VHIS dataset \\
\hline Presenteeism (days) & 20.7 & 20 & 23 & Simulated data using VHIS dataset \\
\hline Premature mortality (deaths) & 29068 & 23759 & 38334 & International Diabetes Federation, $2017^{1}$ \\
\hline \multicolumn{5}{|l|}{ Income (US\$)* } \\
\hline Female & 2683 & 1878 & 3488 & $\begin{array}{l}\text { General statistics of Viet Nam, } 2017 \text { and self- } \\
\text { reported income from the survey* }\end{array}$ \\
\hline Discount rate (\%) & 3 & 0 & 6 & WHO guide to cost-effectiveness analysis \\
\hline
\end{tabular}

*Mean income from General statistics of Viet Nam; the lower and upper values were taken from the survey.

VHIS, Vietnam Health Insurance Scheme. 


\section{Statistical analyses}

Descriptive analyses were conducted for both actual and predicted data. Missing data were not imputed. Only three individuals in the VHIS database had missing information on age and none in the survey. All data analyses were conducted using SPSS V.16.0 ${ }^{15}$ and Microsoft Excel 365 ProPlus. All costs were reported in the United States dollar (US\$) in 2017. No cost adjustment was made due to the short time gap between the information in the dataset (January to December 2017) and the conduct of the survey (June and July 2018).

\section{Ethics approval}

The research protocol was approved by the Research Council of Hanoi University of Pharmacy in Hanoi, Vietnam (Approval ID: 1102/QD-DHN/30112015).

\section{RESULTS}

Table 2 presents the description of the demographic and clinical characteristics of patients in the survey and the VHIS database. All eligible patients who were approached agreed to participate in the study. The mean (SD) age of the survey participants was $66.0(10.1)$ years, $51 \%$ were men, and $55 \%$ living in the urban area. The distribution of participants recruited across the different levels of health facilities was comparable: $32 \%$ from the district hospital, 37\% from the provincial hospital and 31\% from the national hospital. About $46 \%$ of the participants had at least one comorbidity and $48 \%$ had diabetes-related complications. There were 1,395, 204 patients who were diagnosed with T2DM in the VHIS database. The mean (SD) age of people with T2DM was 63.0 (11.1) years. About $41 \%$ were men. Around $37 \%$ of the patients had both dyslipidaemia and hypertension, and 55\% had diabetes-related complications.

\section{Annual mean direct non-medical costs and indirect costs obtained from the survey}

The mean (SD) annual direct non-medical costs (shown in figure 1A) and indirect costs (figure 1B) among the survey participants were US $\$ 53$ (US\$79) and US $\$ 185$ (US\$121) respectively. Overall, indirect costs accounted for a higher proportion $(63 \%)$ than direct non-medical costs $(37 \%)$. Of the direct non-medical cost, transportation had the highest mean (SD) cost US\$24 (US\$40), followed by meals US $\$ 16$ (US\$23) and non-prescribed supplements US\$12 (US\$ 34). Paid care (US\$1) and loans (US $\$ 0.3$ ) comprised a very low proportion. Those with complications spent more for all direct non-medical cost components than those without complications (transport: $\$ 336$ vs $\$ 14$; meals: $\$ 18$ vs $\$ 13$; supplements: $\$ 18$ vs $\$ 6$; paid-care: $\$ 2$ vs $\$ 0.2$; loan: $\$ 0.6$ vs $\$ 0)$. Annual mean (SD) presenteeism cost per patient was US\$134 (US\$91), whereas absenteeism cost was US\$51 (US\$42). Each person with complications incurred US\$30 more presenteeism cost and US\$10 more absenteeism cost than an individual without complications.
Table 2 Demographics and medical conditions of type two diabetes survey participants and individuals in VHIS

\begin{tabular}{|c|c|c|}
\hline & $\begin{array}{l}\text { Survey } \\
(n=315) n(\%)\end{array}$ & $\begin{array}{l}\text { National database } \\
(n=1,395204) n(\%)\end{array}$ \\
\hline \multicolumn{3}{|l|}{ Demographics } \\
\hline \multicolumn{3}{|l|}{ Gender } \\
\hline Male & $159(50.5)$ & $573074(41.1)$ \\
\hline Female & $156(49.5)$ & $822130(58.9)$ \\
\hline $\mathrm{Age}^{\star}($ mean $\pm \mathrm{SD})$, years & $66.0 \pm 10.1$ & $63.0 \pm 11.1$ \\
\hline $30-39$ & $2(0.6)$ & $26736(1.9)$ \\
\hline $40-49$ & $17(5.4)$ & $124032(8.9)$ \\
\hline $50-59$ & $60(19.0)$ & $372374(26.7)$ \\
\hline $60-69$ & $117(37.1)$ & 501056 (35.9) \\
\hline $70-79$ & $96(30.5)$ & $262362(18.8)$ \\
\hline$\geq 80$ & $23(7.3)$ & $108641(7.8)$ \\
\hline \multicolumn{3}{|l|}{ Residence } \\
\hline Urban & $173(54.9)$ & $\mathrm{N} / \mathrm{R}$ \\
\hline Rural & $142(45.1)$ & $\mathrm{N} / \mathrm{R}$ \\
\hline \multicolumn{3}{|l|}{ Medical conditions } \\
\hline \multicolumn{3}{|l|}{ Comorbidities } \\
\hline $\begin{array}{l}\text { No dyslipidaemia } \\
\text { and no hypertension }\end{array}$ & $170(54.0)$ & $273318(19.6)$ \\
\hline Hypertension only & $33(10.5)$ & $434582(31.1)$ \\
\hline Dyslipidaemia only & $70(22.2)$ & $168238(12.1)$ \\
\hline $\begin{array}{l}\text { Dyslipidaemia and } \\
\text { hypertension }\end{array}$ & $42(13.3)$ & 519066 (37.2) \\
\hline \multicolumn{3}{|l|}{ Complications } \\
\hline Microvascular & $126(40.0)$ & $189948(13.6)$ \\
\hline Macrovascular & $14(4.4)$ & $368623(26.4)$ \\
\hline $\begin{array}{l}\text { Both microvascular } \\
\text { and macrovascular }\end{array}$ & $10(3.2)$ & $196513(14.1)$ \\
\hline None & $165(52.4)$ & $640120(45.9)$ \\
\hline
\end{tabular}

*three missing cases in the VHIS national database.

$\mathrm{N} / \mathrm{R}$, Not reported in the database.

Predicted annual mean direct non-medical costs, absenteeism cost and presenteeism cost amongst VHIS enrollees

As shown in table 3, compared with VHIS female enrollees, male enrollees bore higher direct non-medical cost (US\$60 vs US\$53), absenteeism cost (US\$62 vs US\$58) and presenteeism cost (US\$276 vs US\$252). Although the costs of presenteeism and absenteeism were positively associated with age, this trend was not salient for direct non-medical cost. Patients with diabetes-related complications incurred twice as much direct non-medical costs as those without complication (mean cost per person (SD): US\$74 (US\$17) vs US\$34 (US\$9)). Similarly, complications were also associated with higher absenteeism costs (mean cost per person (SD): US $\$ 74$ (US\$53) vs US\$ 49 (US\$36)). However, the difference in presenteeism costs between those with and without complications was 

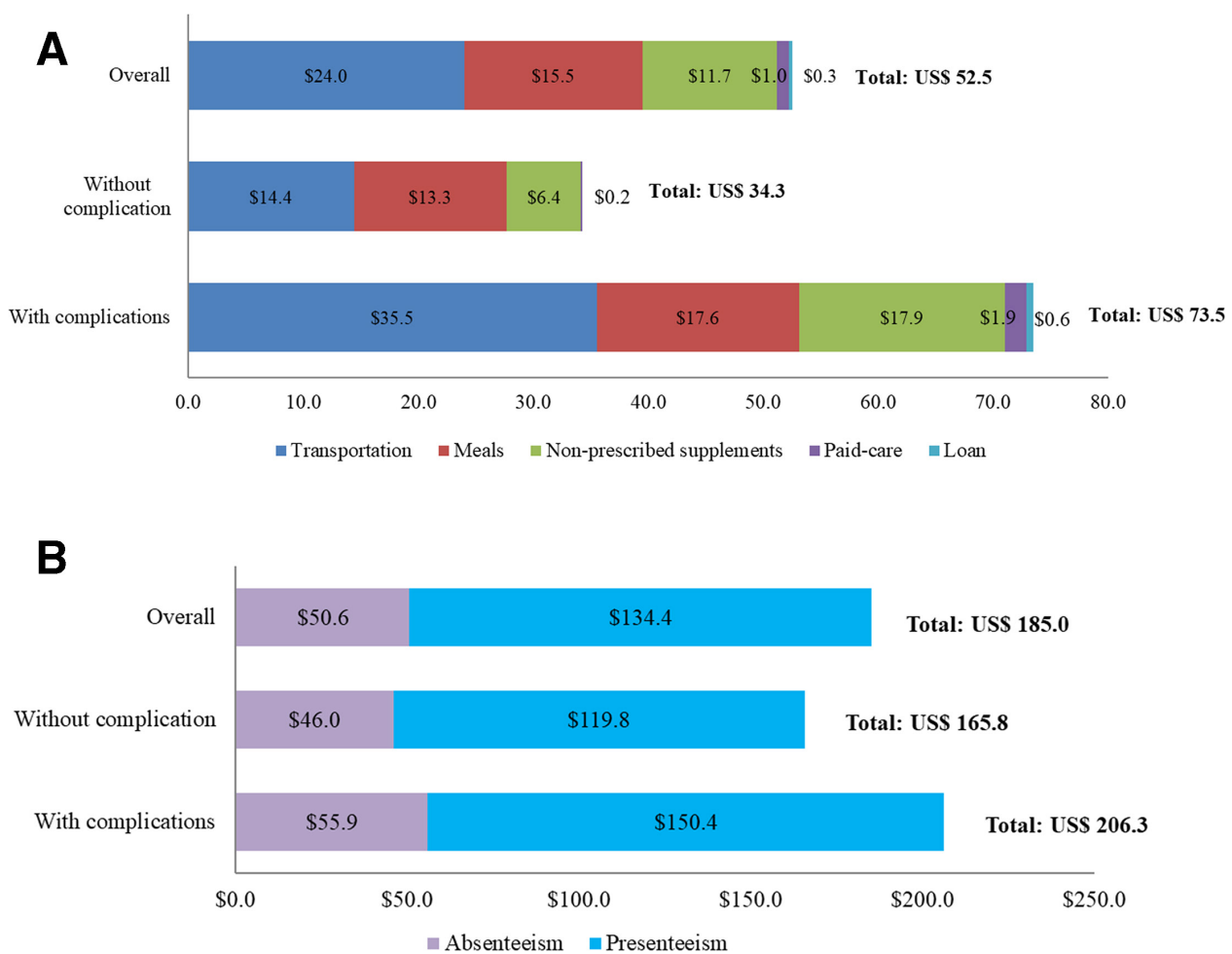

Figure 1 (A) Annual mean direct non-medical cost of 315 patients in a cross-sectional survey. (B) Annual mean indirect cost of 315 patients in a cross-sectional survey.

not remarkable (mean cost per person (SD): US\$266 (US\$39) vs US\$267 (US\$32)). No associations were seen with the comorbidities and direct non-medical cost.

\section{Predicted total national direct non-medical and indirect costs} Online supplementary table 3 shows the breakdown of the total costs. Direct non-medical costs were projected to be around US $\$ 78$ million for the VHIS enrollees. Total indirect costs of US $\$ 161$ million comprised US $\$ 27$ million absenteeism costs, US $\$ 118$ million presenteeism costs and US $\$ 17$ million due to premature mortality. The latter was based on 4882 diabetes-related deaths of working age in Vietnam in 2017, as reported in the IDF and 1885 deaths in the IHME. Of the total direct non-medical and indirect costs, presenteeism accounted for the highest proportion $(49 \%)$, followed by direct non-medical cost (33\%), absenteeism $(11 \%)$ and mortality $(7 \%)$.

\section{Sensitivity analyses}

One-way sensitivity analyses (in figure 2) showed that income was the most sensitive to variations, resulting in total direct non-medical and indirect costs ranging from US $\$ 191$ million to US $\$ 287$ million (or $-21 \%$ to $20 \%$, respectively, of the base case). The least influential parameter was the discount rate, which resulted in a variation of around $1 \%$ on the base case of direct non-medical and indirect costs.

Probabilistic sensitivity analyses revealed a mean (SD) total direct non-medical costs of US\$78 million (US\$34 million) in direct non-medical costs. The minimum and maximum values were US\$6 million and US\$262 million, respectively. Mean (SD), minimum and maximum values of total indirect costs were US\$161 million (US $\$ 37$ million), US\$105 million and US\$313 million, respectively.

\section{DISCUSSION}

Direct non-medical and indirect costs are invisible to the government, but they are not invisible to society. This study found that the total direct non-medical and indirect costs due to diabetes amounted to US\$239 million in 2017, with the main driver being presenteeism at $49 \%$ of the costs. Our study showed that patients with diabetes-related complications could sustain direct non-medical costs and absenteeism costs, which were two times higher than patients without complications. Presenteeism costs for both groups were found to be similar. The robustness of the estimation was investigated by sensitivity analyses. Variation in income revealed the largest change in the total direct non-medical and indirect cost estimates. Another study examining the direct medical cost found that the annual direct medical costs per person with complications (US\$398) were almost twice as that for one without complications (US\$206) in the same year of study. ${ }^{16}$ With this said, the direct non-medical costs and indirect costs were more than the direct medical costs and this could hamper patients' willingness to seek prompt diagnosis and treatment.

The cost estimates in this study are potentially underestimated due to a few factors. First, the VHIS database included 1.4 million T2DM-treated patients. In contrast, the IDF estimated that there are 3.5 million adults with T1DM or T2DM, of which around half ( $49 \%$ or 1.7 million) are diagnosed. ${ }^{1}$ Second, this study did not consider costs for 
Table 3 Annual mean direct non-medical cost, absenteeism cost and presenteeism cost of patients with type2 diabetes in Vietnam $(2017$, US\$)

\begin{tabular}{|c|c|c|c|c|c|c|}
\hline & \multicolumn{6}{|c|}{ Annual mean cost (SD) } \\
\hline & \multicolumn{3}{|l|}{ Survey } & \multicolumn{3}{|c|}{ National database } \\
\hline & $\begin{array}{l}\text { Direct non- } \\
\text { medical }\end{array}$ & Absenteeism & Presenteeism & $\begin{array}{l}\text { Direct non- } \\
\text { medical }\end{array}$ & Absenteeism & Presenteeism \\
\hline Overall & $52.5(79.1)$ & $50.6(41.9)$ & $134.4(90.7)$ & $55.5(24.3)$ & $60.5(45.8)$ & $266.7(35.2)$ \\
\hline \multicolumn{7}{|l|}{ Demographics } \\
\hline \multicolumn{7}{|l|}{ Gender } \\
\hline Male & $56.1(78.0)$ & $55.5(35.9)$ & $155.2(108.0)$ & $59.8(26.1)$ & $62.1(47.0)$ & $276.3(33.7)$ \\
\hline Female & $48.9(61.4)$ & $43.7(20.7)$ & $104.8(85.3)$ & $53.2(22.4)$ & $57.8(43.6)$ & $252.4(32.6)$ \\
\hline \multicolumn{7}{|l|}{ Age (years) } \\
\hline 30-39 & $26.5(0.0)$ & $49.1(0.0)$ & $130.3(0.0)$ & $39.6(18.2)$ & $51.2(39.6)$ & $247.8(20.3)$ \\
\hline $40-49$ & $26.6(23.8)$ & $45.3(21.1)$ & $73.2(34.2)$ & $50.2(23.0)$ & $55.6(42.8)$ & $259.0(27.5)$ \\
\hline $50-59$ & $45.5(55.3)$ & $53.8(45.4)$ & $110.0(96.6)$ & $57.0(26.9)$ & $63.0(47.0)$ & $270.9(37.4)$ \\
\hline $60-69$ & $51.7(57.4)$ & $48.2(21.6)$ & $150.7(98.3)$ & $50.9(20.9)$ & $69.6(48.7)$ & $284.1(42.8)$ \\
\hline $70-79$ & $63.2(92.6)$ & $51.4(19.4)$ & $175.6(106.8)$ & $60.9(21.9)$ & NA & NA \\
\hline$\geq 80$ & $51.8(79.0)$ & $58.5(20.6)$ & $178.9(160.9)$ & $73.3(25.0)$ & NA & NA \\
\hline \multicolumn{7}{|l|}{ Medical conditions } \\
\hline \multicolumn{7}{|l|}{ Comorbidities } \\
\hline $\begin{array}{l}\text { No dyslipidaemia } \\
\text { and no } \\
\text { hypertension }\end{array}$ & 46.3 (66.3) & $47.8(23.8)$ & $132.9(90.7)$ & $41.1(17.1)$ & $46.1(35.9)$ & $291.1(38.7)$ \\
\hline $\begin{array}{l}\text { Hypertension } \\
\text { only }\end{array}$ & $66.9(88.0)$ & $52.1(65.0)$ & $98.7(76.5)$ & $68.6(26.1)$ & $62.8(47.9)$ & $249.6(20.8)$ \\
\hline $\begin{array}{l}\text { Dyslipidaemia } \\
\text { only }\end{array}$ & $49.7(47.2)$ & $55.1(25.2)$ & $146.3(121.8)$ & $35.3(14.2)$ & $55.4(38.4)$ & $278.9(36.5)$ \\
\hline $\begin{array}{l}\text { Dyslipidaemia } \\
\text { and hypertension }\end{array}$ & $71.3(96.4)$ & $55.2(21.5)$ & $164.8(145.1)$ & $59.8(19.7)$ & $75.2(51.3)$ & $249.7(21.1)$ \\
\hline \multicolumn{7}{|l|}{ Complications } \\
\hline Without & $34.3(41.2)$ & $46.0(37.1)$ & $119.8(92.9)$ & $34.2(8.9)$ & $49.5(35.8)$ & $266.4(39.4)$ \\
\hline $\begin{array}{l}\text { With } \\
\text { complications }\end{array}$ & $73.5(88.8)$ & $55.9(21.2)$ & $150.4(109.7)$ & $73.6(17.4)$ & $74.3(52.5)$ & $267.2(31.5)$ \\
\hline
\end{tabular}

NA: when absenteeism and presenteeism were not calculated for patients over working age.

NA, not applicable.

those with undiagnosed diabetes. A study conducted in 2017 in the USA reported that undiagnosed diabetes $(\$ 4250)$ incurred lower costs than diagnosed cases $(\$ 13,240)$. Further research is required to ascertain if this phenomenon is consistent with those in Vietnam. Third, the cost of disability was not included. Although we collected data on disability in the survey, we were unable to simulate to the national level due to the small number of participants reporting disability $(n=12)$. Finally, this study estimated absenteeism and presenteeism only for the working-age population. However, data from the Vietnam Household Living Standard Survey (VHLSS) ${ }^{17}$ showed that $43 \%$ of the elderly aged 60 and above are still working, either part-time or full-time. Therefore, our estimate on productivity loss could be underestimated.

\section{Comparison of results with studies conducted in Vietnam}

To the best of our knowledge, this is the first nationwide study that estimates the direct non-medical costs and indirect costs of patients with T2DM. Costs from survey participants were used to predict costs for all patients enrolled in the VHIS using demographic and clinical characteristics. Compared with the findings in this study, similar research conducted by Le et al. in a tertiary hospital in Vietnam estimated lower direct non-medical costs (US\$56 vs U\$34) and presenteeism costs (US\$267 vs US $\$ 114$ ), but higher absenteeism costs (US\$67 vs US\$61). ${ }^{7}$ The difference in direct non-medical costs could be attributed to the inclusion of different cost components. Le et al. considered only transportation costs as direct non-medical costs, whereas this study also included non-prescribed supplements or 


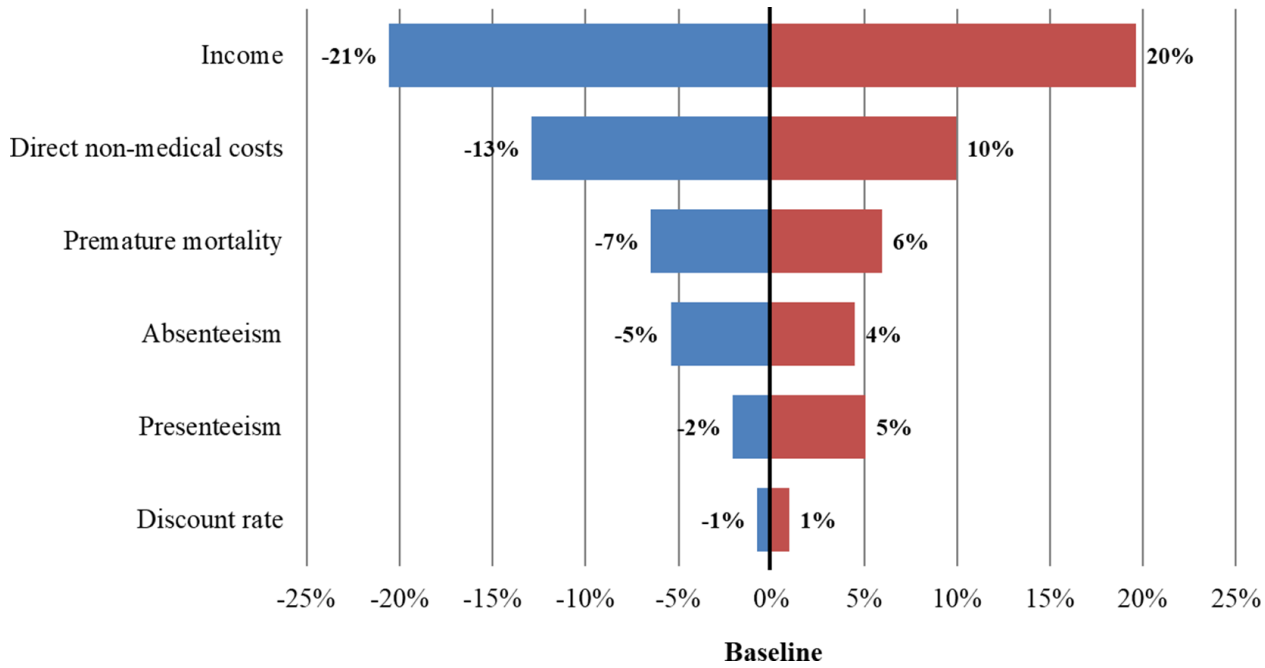

Figure 2 Percentage change in total costs of direct non-medical and indirect costs from a mean of US $\$ 240$ million in response to variation in input parameters.

traditional medicine, meals and loans. The methodology for estimating presenteeism was also different between the two studies. Although the study by Le $e t a l$. determined presenteeism costs based on estimates from a study conducted in the USA, this study obtained estimates from patient surveys. Notably, Le et al. also attempted to assess presenteeism using patient surveys, although the method of assessment was not elaborated. The authors did not use the findings from the survey as they deemed that the estimates were "not accurate as workers, especially labourers, depend on daily productivity for their income' ${ }^{7}$ Our study employed the use of WLQ which has been extensively tested and validated to measure general health impact. The lower estimates of mean absenteeism cost in our study compared with the study by Le $e t$ al. could be attributed to two factors. First, the previous study was conducted in a tertiary hospital, which was more likely to manage patients with more severe conditions, whereas the present study also included patients seen at lower-level facilities. Second, the number of workdays lost was obtained from the VHIS database, which is less susceptible to recall bias.

\section{Comparison of results with studies conducted in other countries}

Studies on direct non-medical and indirect costs of diabetes have been carried out in many parts of the world. ${ }^{18}$ Methodological heterogeneity and variation in the inclusion of cost components limit the comparison of our study findings with other countries. A study published in The Lancet using a top-down and human-capital approach estimated that indirect costs accounted for $35 \%$ of the global economic burden of diabetes. ${ }^{19}$ Labor-force dropout (49\%) and mortality $(46 \%)$ were the biggest contributors to indirect cost. In contrast, individual studies conducted in many countries using a bottom-up approach and involving various settings reported different findings. For instance, a study conducted by the American Diabetes Association (ADA) using data sources from national surveys, Medicare and claims databases for the commercially insured population in the USA found that disease-related disability was the biggest component $(42 \%)$ of indirect cost. $^{20}$ Another study in Poland using the national administrative database and human-capital approach found that presenteeism was dominant at $75 \%$ of the indirect costs. ${ }^{21}$ In terms of costs as a percentage of GDP, direct non-medical and indirect cost accounted for $6.3 \%$ of Thailand per capita GDP in $2008^{3}$ and $7.7 \%$ of Brazil per capita GDP in 2012. ${ }^{22}$ Our study also reported a similar burden of US $\$ 171$ at $7.2 \%$ per capita GDP.

There is strong evidence of the association between direct medical costs and diabetes complications. ${ }^{23}{ }^{24}$ However, less is known about the impact of diabetes-related complications on direct non-medical and indirect costs. This study found that patients with complications incurred higher costs of direct non-medical and indirect costs than those with complications, which is consistent with the findings from a population-based cost-of-illness study in India. ${ }^{25}$ The authors reported a linear relationship between the number of diabetes-related complications and indirect costs. Patients with one, two, three and four or more complications, respectively, incurred 0.9, 1, 3 and 9 times the indirect costs sustained by those without complications. These findings suggest that keeping diabetes under control reduces out-of-pocket costs borne by patients and financial burden for employers due to lost productivity. Although more government interventions are warranted to keep diabetes at bay, it is equally important to improve control among patients with diabetes. Providing financial incentives for patients with diabetes to seek continued treatment should also be considered. Several interventions recommended by the ADA were found to be cost-effective and should be explored and contextualised by the local government. ${ }^{26}$ Future studies could investigate the effect of interventions on the long-term costs of diabetes and its complications.

\section{Strengths and limitations}

The strengths of the study are predicated on the twophase approach. The first phase entailed a cross-sectional 
survey that included patients from different levels of health facilities, capturing patients with varying diabetes-related complications. Although patients with more severe complications are expected to be seen at a higher level of facilities, smaller district-based facilities would see more patients with no or mild complications. The second phase involved the simulation of the survey data to population-level using a nationwide database, which increases the generalisability of the findings. This study has a few limitations. The findings could only be applied to patients who sought healthcare in Vietnam. In addition, a friction-cost approach would ideally serve as part of the sensitivity analyses. This could not be performed due to the lack of data in Vietnam, specifically the disease-specific employment rates. Nevertheless, probabilistic sensitivity analysis has revealed little deviation from the primary estimate.

\section{Conclusion and implications}

This study estimated that the total direct non-medical and indirect costs due to diabetes at US\$239 million in 2017. Presenteeism was the biggest driver at $49 \%$, followed by direct non-medical costs at 33\%. Diabetes-related complications were also shown to have a salient impact on the direct non-medical costs and costs due to absenteeism. The potential impact of costs related to diabetes must be considered and, in other settings, have been significant. Such estimates are also important to be incorporated in the costeffectiveness analysis of interventions targeting diabetes, as it affects multiple vital organ systems. Efforts should be intensified to keep diabetes under control to reduce the financial burden on both patients and their employers.

Acknowledgements The authors would like to show our appreciation to $\mathrm{Mr}$ Tran Tien Hung from Vietnam Social Security in facilitating the data extraction. They would also like to thank Miss Chen Chuang from IQVIA Advanced Analytics Shanghai Hub for providing extensive statistical advice.

Contributors All authors have made substantial contributions: TTMK: planned this study, collected data, performed the analysis, and wrote the article. TBN, HNT and HTKP: participated in the discussions concerning the study design and data collection. JN: planned this study, performed the analysis, interpretation of the results and wrote the article. All authors approved the final draft for submission.

Funding The authors have not declared a specific grant for this research from any funding agency in the public, commercial or not-for-profit sectors.

Competing interests HTKP reports previously receiving funding from Novo Nordisk as experts. JYSN is employed by IQVIA, a contract research organization.

Patient consent for publication Not required.

Ethics approval Research Council of Hanoi University of Pharmacy (Approval ID: 1102/QD-DHN/30112015).

Provenance and peer review Not commissioned; externally peer reviewed.

Data availability statement Data may be obtained from a third party and are not publicly available. The survey data are not publicly available due to ethical restrictions on participant privacy. Data for this study are available upon request to others in the scientific community. For access, please contact Miss Thi Tuyet Mai Kieu: kieumai210@gmail.com. The authors do not have permission to share the national health insurance data. Requests for access should be directed to the Vietnam Social Security.

Open access This is an open access article distributed in accordance with the Creative Commons Attribution Non Commercial (CC BY-NC 4.0) license, which permits others to distribute, remix, adapt, build upon this work non-commercially, and license their derivative works on different terms, provided the original work is properly cited, appropriate credit is given, any changes made indicated, and the use is non-commercial. See: http://creativecommons.org/licenses/by-nc/4.0/.

\section{ORCID iD}

Junice Yi Siu Ng http://orcid.org/0000-0003-3072-0386

\section{REFERENCES}

1 IDF. IDF diabetes atlas 8th edition. Brussels, Belgium: International Diabetes Federation, 2017.

2 Bermudez-Tamayo C, Besançon S, Johri M, et al. Direct and indirect costs of diabetes mellitus in Mali: a case-control study. PLoS One 2017;12:e0176128.

3 Chatterjee S, Riewpaiboon A, Piyauthakit P, et al. Cost of diabetes and its complications in Thailand: a complete picture of economic burden. Health Soc Care Community 2011;19:289-98.

4 Tharkar S, Devarajan A, Kumpatla S, et al. The socioeconomics of diabetes from a developing country: a population based cost of illness study. Diabetes Res Clin Pract 2010;89:334-40.

5 Kirigia JM, Sambo HB, Sambo LG, et al. Economic burden of diabetes mellitus in the who African region. BMC Int Health Hum Rights 2009;9:6.

6 Nguyen HL. The economic burden of diabetes in households with diabetes patients in Hue City. Hue College of Medicine and Pharmacy, 2010.

7 Le NTD, Dinh Pham L, Quang Vo T. Type 2 diabetes in Vietnam: a cross-sectional, prevalence-based cost-of-illness study. Diabetes Metab Syndr Obes 2017;10:363-74.

8 Mafauzy M, Hussein Z, Chan SP. The status of diabetes control in Malaysia: results of DiabCare 2008. Med J Malaysia 2011;66:175-81.

$9 \mathrm{Ng}$ JYS, Ramadani RV, Hendrawan D, et al. National health insurance databases in Indonesia, Vietnam and the Philippines. Pharmacoecon Open 2019;3:517-526.

10 Glasheen WP, Renda A, Dong Y. Diabetes Complications Severity Index (DCSI)-Update and ICD-10 translation. J Diabetes Complications 2017;31:1007-13.

11 Sweeney S, Mukora R, Candfield S, et al. Measuring income for catastrophic cost estimates: limitations and policy implications of current approaches. Soc Sci Med 2018;215:7-15.

12 ILO. Statistical update on employment in the informal economy: international labour organization, 2011.

13 Lerner D, Amick BC, Rogers WH, et al. The work limitations questionnaire. Med Care 2001;39:72-85.

14 Institute for Health Metrics and Evaluation. GBD results tool: Institute for health metrics and evaluation, 2017.

15 IBM SPSS Statistics for Windows.. Version 24.0. Armonk, NY: IBM Corp. 2016.

16 Pham. Direct medical costs of diabetes and its complications in Vietnam: a national health insurance database study. Available: https://www.diabetesresearchclinicalpractice.com/article/S01688227(19)31439-1/fulltext

17 The United Nations Population Fund. The ageing population in Viet Nam: current status, prognosis, and possible policy responses, 2011.

18 Seuring T, Archangelidi O, Suhrcke M. The economic costs of type 2 diabetes: a global systematic review. Pharmacoeconomics 2015;33:811-31.

19 Bommer C, Heesemann E, Sagalova V, et al. The global economic burden of diabetes in adults aged 20-79 years: a cost-of-illness study. Lancet Diabetes Endocrinol 2017;5:423-30.

20 American Diabetes Association. Economic costs of diabetes in the U.S. in 2017. Diabetes Care 2018;41:917-28.

21 Torój A, Mela A. Indirect costs of diabetes and its impact on the public finance: the case of Poland. Expert Rev Pharmacoecon Outcomes Res 2018;18:93-105.

22 Borges NB, Ferraz MB, Chacra AR. The cost of type 2 diabetes in Brazil: evaluation of a diabetes care center in the city of São Paulo, Brazil. Diabetol Metab Syndr 2014;6:122.

$23 \mathrm{Ng}$ CS, Lee JYC, Toh MP, et al. Cost-Of-Illness studies of diabetes mellitus: a systematic review. Diabetes Res Clin Pract 2014;105:151-63.

24 Dall TM, Zhang Y, Chen YJ, et al. The economic burden of diabetes. Health Aff 2010;29:297-303.

25 Tharkar S, Satyavani K, Viswanathan V. Cost of medical care among type 2 diabetic patients with a co-morbid condition--hypertension in India. Diabetes Res Clin Pract 2009;83:263-7.

26 Li R, Zhang P, Barker LE, et al. Cost-Effectiveness of interventions to prevent and control diabetes mellitus: a systematic review. Diabetes Care 2010;33:1872-94. 